\title{
Net primary production of a temperate deciduous forest exhibits a threshold response to increasing disturbance severity
}

\author{
Ellen J. Stuart-Haëntjens, ${ }^{1,5}$ Peter S. Curtis, ${ }^{2}$ Robert T. Fahey, ${ }^{3}$ Christoph S. Vogel,${ }^{4}$ \\ and Christopher M. Gough ${ }^{1}$ \\ ${ }^{1}$ Virginia Commonwealth University, Department of Biology, Box 842012, 1000 West Cary Street, Richmond, Virginia 23284-2012 USA \\ ${ }^{2}$ Ohio State University, Department of Evolution, Ecology and Organismal Biology, 318 West 12th Avenue, Columbus, Ohio 43210 USA \\ ${ }^{3}$ The Morton Arboretum, 4100 Illinois Route 53, Lisle, Illinois 60532 USA \\ ${ }^{4}$ University of Michigan Biological Station, 9008 Biological Road, Pellston, Michigan 49769 USA
}

\begin{abstract}
The global carbon (C) balance is vulnerable to disturbances that alter terrestrial C storage. Disturbances to forests occur along a continuum of severity, from low-intensity disturbance causing the mortality or defoliation of only a subset of trees to severe standreplacing disturbance that kills all trees; yet considerable uncertainty remains in how forest production changes across gradients of disturbance intensity. We used a gradient of tree mortality in an upper Great Lakes forest ecosystem to: (1) quantify how aboveground wood net primary production $\left(\mathrm{ANPP}_{\mathrm{w}}\right)$ responds to a range of disturbance severities; and (2) identify mechanisms supporting $\mathrm{ANPP}_{\mathrm{w}}$ resistance or resilience following moderate disturbance. We found that $\mathrm{ANPP}_{\mathrm{w}}$ declined nonlinearly with rising disturbance severity, remaining stable until $>60 \%$ of the total tree basal area senesced. As upper canopy openness increased from disturbance, greater light availability to the subcanopy enhanced the leaf-level photosynthesis and growth of this formerly light-limited canopy stratum, compensating for upper canopy production losses and a reduction in total leaf area index (LAI). As a result, whole-ecosystem production efficiency $\left(\mathrm{ANPP}_{\mathrm{w}} / \mathrm{LAI}\right)$ increased with rising disturbance severity, except in plots beyond the disturbance threshold. These findings provide a mechanistic explanation for a nonlinear relationship between $\mathrm{ANPP}_{\mathrm{w}}$ and disturbance severity, in which the physiological and growth enhancement of undisturbed vegetation is proportional to the level of disturbance until a threshold is exceeded. Our results have important ecological and management implications, demonstrating that in some ecosystems moderate levels of disturbance minimally alter forest production.
\end{abstract}

Key words: canopy; carbon cycling; disturbance; leaf area index (LAI); light; mortality; net primary production; northern Michigan, USA, forest; production efficiency; resilience; resistance.

\section{INTRODUCTION}

Forests store $1.1 \pm 0.8 \mathrm{Pg}$ carbon $(\mathrm{C})$ annually in biomass, soils, and organic matter (Pan et al. 2011) and contain $60 \%$ of the Earth's terrestrial C stocks (McKinley et al. 2011). Yet the future strength of this large terrestrial $\mathrm{C}$ sink is uncertain as disturbances increase in global extent and frequency (Amiro et al. 2010, Pan et al. 2011, Hicke et al. 2012). Severe stand-replacing disturbance events such as high-intensity fire or clear-cut harvest reduce rates of $\mathrm{C}$ storage by decreasing net primary production (NPP) and increasing the rate at which $\mathrm{C}$ is cycled back to the atmosphere through decomposition (Amiro et al. 2010, Peckham et al. 2013). Considerably less is known about how forest $\mathrm{C}$ storage responds to disturbances such as extreme weather, pathogens, insects, and age-related senescence that kill or defoliate only a fraction of canopy dominant trees. As

Manuscript received 20 September 2014; revised 18 February 2015; accepted 9 March 2015. Corresponding Editor: P. H. Templer.

${ }^{5}$ E-mail: goodrichstej@vcu.edu a result, our understanding of how NPP responds to disturbance is derived almost entirely from severe disturbance events, limiting forecasts of $\mathrm{C}$ storage for the range of disturbance severities represented across landscapes (Goetz et al. 2012, Hicke et al. 2012).

The response of forest production to incremental increases in disturbance severity is likely to proceed in one of three ways (Fig. 1). The first potential response in the short term is a linear decline in NPP with increasing disturbance severity, which is collectively suggested by studies of forest ecosystems following a single level of disturbance severity, which show production losses are approximately proportional to disturbance severity (Hicke et al. 2012). The second is a precipitous, nonlinear reduction in NPP at low disturbance severities, a response observed in aquatic ecosystems when a subset of primary producers is lost from the community (Cardinale et al. 2011). Lastly, studies conducted in constructed prairie (e.g., Tilman et al. 2001) and in some forests (Amiro et al. 2010, Hicke et al. 2012, Gough et al. 2013) suggest a nonlinear response, in which NPP is insensitive (i.e., is resistant) or shows very rapid 


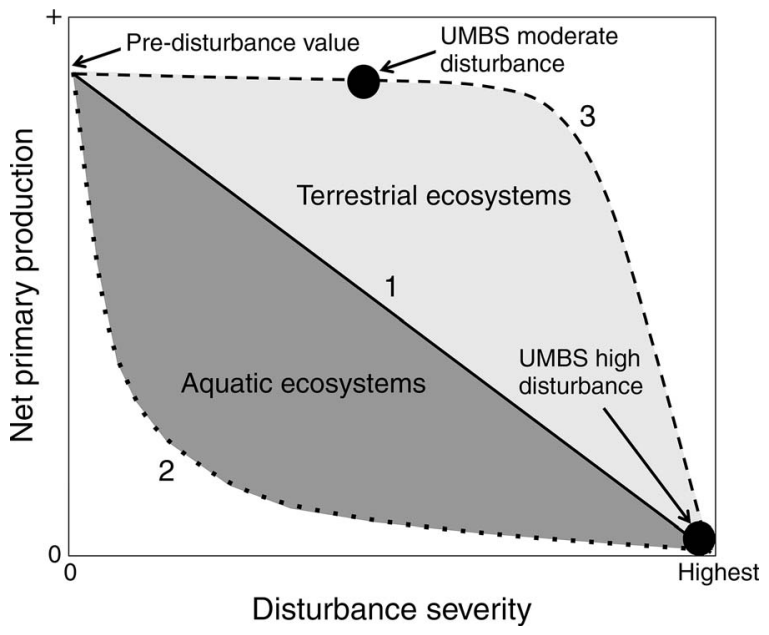

FIG. 1. Three potential generalized responses of net primary production to disturbance severity based on experiments and observations in terrestrial and aquatic ecosystems: (1) a linear decline (Hicke et al. 2012), (2) a nonlinear, highsensitivity response (Cardinale et al. 2011), and (3) a nonlinear, threshold response (e.g., Tilman et al. 2001). Each response has limited support from prior studies of disturbance or species removal in aquatic or terrestrial ecosystems, with publications providing evidence for each cited. A threshold response is suggested by landscape-scale studies conducted at our study site, the University of Michigan Biological Station (UMBS).

resilience to increasing disturbance levels or species loss up to a threshold, after which production abruptly declines. Here, resilience describes a temporary shift in ecosystem structure and function, NPP in this case, while resistance indicates a change in structure but not functional stability, with recognition that different functions have varying capacities for resilience and resistance (Gunderson 2000). Strong evidence for one or more of these relationships in forested ecosystems is lacking because few studies have examined how the NPP of an individual ecosystem changes across a disturbance severity gradient, and those studies that have are inconclusive (see Hancock et al. 2008).

In forests, compensatory subcanopy growth plays a key mechanistic role in sustaining NPP following moderate disturbances that defoliate or kill a fraction of canopy-dominant trees (Le et al. 2007, Campbell et al. 2009). As upper-canopy trees senesce and gaps form, newly available light may stimulate the growth of previously light-limited vegetation (Edburg et al. 2011, Nave et al. 2011, Yang et al. 2011). Although compensatory growth is a well-established mechanism sustaining production immediately following disturbance, the underlying mechanisms that stimulate or suppress subcanopy production across a continuum of disturbance severity are not well known (Sabo et al. 2008, Campbell et al. 2009). Identifying the mechanisms that sustain or, conversely, cause production to decline is critical to determining why and when $\mathrm{C}$ storage will change as disturbance severity increases (Amiro et al. 2010, Hicke et al. 2012).

We build on biogeochemical studies at the University of Michigan Biological Station (UMBS) centered on a large-scale (39-ha) experimental disturbance in which all mature aspen (Populus) and birch (Betulacea) were killed by stem girdling in 2008. The experiment has yielded mechanistic insight into $\mathrm{C}$, nitrogen $(\mathrm{N})$, and water-cycling responses to moderate disturbance (Nave et al. 2011, 2014, Gough et al. 2013, Matteo al. 2013, He et al. 2014, Matheny et al. 2014a, b). Results in the first five years following disturbance demonstrate that mean NPP of the manipulated area was sustained despite the mortality of more than a third of all canopy trees (Nave et al. 2011, Gough et al. 2013). Here, we use a broad gradient of disturbance severity, from $9 \%$ to $69 \%$ senesced basal area, within the large manipulated area to: (1) quantify how aboveground wood net primary production $\left(\mathrm{ANPP}_{\mathrm{w}}\right)$ responds to a range of disturbance severities and; (2) identify the primary mechanisms sustaining production following moderate disturbance. Given prior results from our site showing high resistance to moderate disturbance at the landscape scale and substantial reductions in production following severe disturbance (Gough et al. 2013), we postulated that $\mathrm{ANPP}_{\mathrm{w}}$ would respond nonlinearly to increasing disturbance severity, remaining stable as disturbance intensity increases, before declining. We predicted that the subcanopy would play a critical role in sustaining $\mathrm{ANPP}_{\mathrm{w}}$ following disturbance, but at higher disturbance levels mortality would be too severe to be fully offset by compensatory subcanopy growth.

\section{Materials And Methods}

\section{Study site}

We conducted our study at UMBS in northern Michigan, USA $\left(45^{\circ} 35^{\prime} \mathrm{N}, 84^{\circ} 43^{\prime} \mathrm{W}\right)$. The area has a mean annual temperature of $5.5^{\circ} \mathrm{C}$ and a mean annual precipitation of $817 \mathrm{~mm}$ (1942-2003) (Gough et al. 2013). Prior to experimental disturbance, the landscape was largely composed of century-old maturing aspendominated forest that developed following massive clear-cut harvesting and wildfires in the early 20th century. Bigtooth aspen (Populus grandidentata), trembling aspen (Populus tremuloides), and paper birch (Betula papyrifera), all short-lived early-successional species, once dominated the upper canopy and are now in natural decline. Red oak (Quercus rubra) and red maple (Acer rubrum) are gaining dominance in the upper canopy, with lesser representation of sugar maple (Acer saccharum), eastern white pine (Pinus strobus), and American beech (Fagus grandifolia). The subcanopy, the canopy stratum 1 to $5 \mathrm{~m}$ above the forest floor, is dominated mainly by red maple and red oak, and also includes American beech, sugar maple, Amelanchier arboria (serviceberry), Acer pensylvanicum (striped maple), white pine, Pinus resinosa (red pine), and Ostrya virginiana (American hophornbeam). Trees $\geq 8 \mathrm{~cm}$ diam- 
eter at breast height (dbh, $1.37 \mathrm{~m}$ ) have a stem density of $700-800$ trees/ha, a basal area (BA) of $\sim 25 \mathrm{~m}^{2} / \mathrm{ha}$, and the forest has a mean leaf area index (LAI) of 3.5.

In May 2008, the Forest Accelerated Succession Experiment (FASET) was initiated to examine how ecological succession and disturbance affect $\mathrm{C}$ cycling in a broadly distributed regionally representative forest ecosystem (Nave et al. 2011). All aspen and birch trees (>6700) comprising $39 \%$ of the pre-treatment basal area were stem girdled within a 39-ha area to test the primary hypothesis that net ecosystem production (NEP) will increase as the canopy becomes more biologically and structurally complex, and as nitrogen $(\mathrm{N})$ is reallocated from early to later successional canopy dominants. Peak disturbance within the large treatment area occurred in 2010 , when $97 \%$ of all girdled trees had senesced and leaf area index was $44 \%$ lower than pre-disturbance values (Gough et al. 2013).

Our study encompasses a large gradient in disturbance severity, while minimizing the effects of variables that could confound the relationship between production and disturbance severity. Within the large manipulated area, we defined disturbance severity in each of $21,0.8$-ha plots as the fraction of BA ( $\geq 8 \mathrm{~cm} \mathrm{dbh})$ that senesced from stem girdling; accordingly, we use "disturbance severity" and "fraction of senesced basal area" interchangeably. We use this expression of disturbance severity because basal area is a direct rather than inferred or derived (e.g., LAI or biomass) measure of forest structure available for every plot, and made with high certainty (Gough et al. 2008). Plots were located at $100-\mathrm{m}$ intervals along seven transects radiating from the base of the meteorological tower (Gough et al. 2013). We estimated subcanopy and canopy, and total $\mathrm{ANPP}_{\mathrm{w}}$ in all 21 plots using methods below. Of the 21 plots, a subset of 10 "intensive" plots with similar $\mathrm{ANPP}_{\mathrm{w}}$ values and tree species composition prior to peak disturbance was selected for additional analysis. Within each intensive plot, we established four nonoverlapping $5 \mathrm{~m}$ radius subplots along each cardinal axis from plot center for measurements of light, percentage of foliar $\mathrm{N}$, maximum leaf net $\mathrm{CO}_{2}$ assimilation, and canopy openness. Importantly, the $\mathrm{ANPP}_{\mathrm{w}}$ and LAI of all plots and intensive plots only were not correlated with the fraction of senesced basal area prior to peak disturbance $(P>0.9)$, indicating no preexisting relationship between forest production and disturbance severity.

\section{Aboveground wood net primary production $\left(A N P P_{w}\right)$}

We quantified $\mathrm{ANPP}_{\mathrm{w}}$ before and after peak disturbance. We use $\mathrm{ANPP}_{\mathrm{w}}$ as our primary expression of C storage because it is quantified with high certainty and closely parallels more comprehensive, data-intensive measures of $\mathrm{C}$ uptake and storage (i.e., NEP, total NPP) at our site (Gough et al. 2013). Aboveground woody biomass $\left(M_{\mathrm{a}}\right)$ was estimated from dbh measurements of all trees in each of the 21 treatment plots in
2006, 2010, and 2012. Every tree $\geq 8 \mathrm{~cm}$ dbh within a plot was measured for specific dbh. Trees $<8 \mathrm{~cm}$ dbh were assigned to diameter classes: $<2 \mathrm{~cm}, 2-3.9 \mathrm{~cm}, 4-$ $5.9 \mathrm{~cm}$, and $6-7.9 \mathrm{~cm}$. Site or region-specific allometric equations were used to estimate $M_{\mathrm{a}}$ from dbh (Gough et al. 2013). Mean annual $\mathrm{ANPP}_{\mathrm{w}}$ of upper canopy and subcanopy strata was measured as the mean change in total aboveground wood mass between census years, providing a production value leading up to (2006-2010) and following (2010-2012) peak disturbance (Gough et al. 2013).

\section{Litter trap leaf area index}

Leaf area index estimated from litter traps $\left(\mathrm{LAI}_{t}\right)$ was calculated in 2006 for 20 of 21 plots and then annually following disturbance in 6 of the 10 intensive plots. Litterfall from three litter traps $\left(0.264 \mathrm{~m}^{2}\right.$ each $)$ within each plot was collected weekly during leaf-fall and monthly otherwise, dried at $60^{\circ} \mathrm{C}$, separated by species, and weighed. $\mathrm{LAI}_{\mathrm{t}}$ is the product of litterfall mass and specific leaf area (SLA) values (Gough et al. 2013).

\section{Hemispherical imaging}

We used hemispherical images collected in intensive measurement plots at peak LAI in 2013 to examine how disturbance affected canopy structure. Images were taken under diffuse sky conditions in four subplot locations within each plot at ground level, $1 \mathrm{~m}$, and $5 \mathrm{~m}$ vertical heights using a leveled camera with an $180^{\circ}$ fisheye lens facing skyward. We derived estimates of LAI and upper canopy openness $(>5 \mathrm{~m})$ using Gap Light Analyzer (GLA Version 2.0) software with the automatic optimal threshold algorithm applied (Nobis and Hunziker 2005).

We used hemispherical images to estimate total LAI for all 10 intensive plots, since we did not have a complete $\mathrm{LAI}_{\mathrm{t}}$ record of all sites over time, and to calculate the LAI of the upper canopy strata $(\geq 5 \mathrm{~m}$ height). We calibrated estimates of LAI from hemispherical images $\left(\mathrm{LAI}_{\mathrm{h}}\right)$ against $\mathrm{LAI}_{\mathrm{t}}$ measurements, applying a linear correction to $\mathrm{LAI}_{\mathrm{h}}$. The two independently derived estimates of LAI were strongly correlated ( $y=2.6191 x$ $\left.-2.5146 ; r^{2}=0.87 ; P=0.008\right)$.

\section{Light distribution}

We quantified the subcanopy fraction of absorbed photosynthetically active radiation (fAPAR) in intensive plots as PAR absorbed between $5 \mathrm{~m}$ height and ground level. A BF2 sunshine sensor (Delta-T Devices, Cambridge, UK) on a meteorological tower measured total and diffuse PAR above the canopy. Separate PAR sensors (SQ-110 Quantum Sensor, Apogee Instruments, Logan, Utah, USA) were stationed at ground level and 5 $\mathrm{m}$ above the forest floor in four subplot locations within each plot and connected to a central datalogger. To minimize sunflecks, we quantified fAPAR $>4$ hours when light was $>85 \%$ diffuse (e.g., Tobin and Reich 2009), and to reduce the influence of solar angle, the 
PAR time-series from each sensor was averaged. Because of poor diffuse conditions or sensor failure in three plots, we report results from 7 of 10 plots.

\section{Production efficiency}

We evaluated production efficiency across the gradient of disturbance severity. Plot level production efficiency was estimated in our 10 intensive plots as the ratio of $\mathrm{ANPP}_{\mathrm{w}}$ to $\mathrm{LAI}_{\mathrm{h}}$ (McCrady and Jokela 1998).

\section{Leaf physiological, morphological, and nitrogen measurements}

We examined whether subcanopy leaf nutrient status, morphology, and photosynthesis varied with disturbance severity. We measured the light-saturated net $\mathrm{CO}_{2}$ assimilation $\left(A_{\max }\right)$ at $5 \mathrm{~m}$ height of 2-4 fully developed subcanopy leaves in situ in each of four subplots within the intensive plots using a LiCor-6400 Portable Photosynthesis System (LI-COR Incorporated, Lincoln, Nebraska, USA). When available, red oak and red maple were sampled because of their broad dominance in the subcanopy; American beech, the third most dominant subcanopy species, was selected when either red oak or red maple was not present. Following $A_{\max }$ measurements, we harvested leaves to obtain leaf mass per area (LMA) and leaf percent N. Processed leaves were dried at $60^{\circ} \mathrm{C}$, ground in a Wiley mill, and leaf $\mathrm{N}$ concentration quantified using a $\mathrm{CHN}$ analyzer.

\section{Statistical analyses}

We used piecewise regression to evaluate whether $\mathrm{ANPP}_{\mathrm{w}}$ exhibited a threshold response to rising disturbance severity. We chose a piecewise analysis because of a priori observations of high resistance to moderate disturbance at our site (Gough et al. 2013), and because this approach is suitable for testing our hypothesis that production is sustained until a threshold of disturbance is exceeded. Piecewise regression is a "broken-stick" modeling approach used extensively for identifying ecological thresholds and slope transitions (Toms and Lesperance 2003). The procedure iteratively fits multiple linear segments separated by a breakpoint and requires that the following criteria are met: (1) the slope coefficients before and after a threshold are significantly different according to the $F$ statistic; (2) the threshold or breakpoint separating segments is significant according to the $F$ statistic; and (3) the adjusted $r^{2}$ of the piecewise regression is greater than that of the default single-segment linear regression model. If all criteria are not met, the procedure applies a single-segment linear regression model.

We used simple linear regression to examine how disturbance severity related to forest structural, functional, and environmental metrics, including production efficiency, canopy openness, $\mathrm{LAI}_{\mathrm{h}}, A_{\max }$, LMA, and leaf percentage $\mathrm{N}$. Linear regression was used for these analyses because we had no a priori knowledge of how these response variables mathematically relate to disturbance severity. To test whether plots beyond the disturbance threshold had statistically lower production efficiencies, we applied a linear regression to plots exhibiting resistance to disturbance and evaluated whether plots beyond the threshold were outside of the regression $95 \%$ confidence interval; our limited intensive plot sample size $(n=10)$ precluded the application of a piecewise regression. All statistical analyses used SPSS 12.5 (SPSS 2005) or R 3.1.0 (R Development Core Team 2014) statistical software. Relationships were considered significant when $P<0.1$. For continuity among figures, we illustrate non-intensive plots with open circles, disturbance-resistant intensive plots with filled circles, and disturbance-sensitive plots beyond the threshold as half-filled circles.

\section{RESUlts \\ Production and disturbance severity}

Our piecewise regression analysis yielded support for a threshold response of forest production to rising disturbance severity. Two-segment piecewise models expressing absolute and relative changes in $\mathrm{ANPP}_{\mathrm{w}}$ with rising disturbance severity had higher adjusted $r^{2}$ values than single-segment linear models, the slope coefficients for each linear segment were significantly different, and the threshold values were highly significant (Table 1). Production was relatively stable across the gradient of disturbance severity spanning 9-69\% senesced basal area, with $\mathrm{ANPP}_{\mathrm{w}}$ significantly declining only at the highest levels according to both two-segment models. Though our sample size at the highest level of disturbance severity is small $(n=3$ plots with $>60 \%$ senesced basal area), our analysis suggests that absolute and relative changes in $\mathrm{ANPP}_{\mathrm{w}}$ were significant when the fraction of senesced basal area within a plot exceeded $66 \%$ and $61 \%$, respectively (Fig. 2, Table 1). $\mathrm{ANPP}_{\mathrm{w}}$ values below the disturbance threshold were comparable to those of a nearby undisturbed forest (Gough et al. 2013).

\section{Canopy structural and environmental responses to increasing disturbance severity}

Canopy structure varied substantially across the gradient of disturbance severity, affecting the light environment of the subcanopy. The $\mathrm{LAI}_{\mathrm{h}}$ of the upper canopy ( $>5 \mathrm{~m}$ vertical height) decreased significantly with increasing disturbance severity, indicating that plot scale leaf area has not fully recovered five years following the girdling treatment at the highest disturbance levels (Fig. 3a). Upper canopy openness, a measure of canopy gap size, increased by $50 \%$ across the gradient of disturbance (Fig. 3b), with subcanopy light availability increasing in parallel (Fig. 3c). Mean subcanopy fAPAR more than doubled from low to high disturbance severities.

\section{Ecosystem responses to disturbance}

As disturbance severity increased, the subcanopy played an increasingly important role in maintaining 
TABLE 1. Two-segment and single-segment regression coefficients and statistics for relationships between absolute and relative (\%) changes in $\mathrm{ANPP}_{\mathrm{w}}\left(\triangle \mathrm{ANPP}_{\mathrm{w}}\right)$ and disturbance severity.

\begin{tabular}{|c|c|c|c|c|c|c|c|c|c|c|}
\hline \multirow[b]{2}{*}{$\Delta \mathrm{ANPP}_{\mathrm{w}}$} & \multicolumn{5}{|c|}{ Two-segment } & \multicolumn{5}{|c|}{ Single-segment } \\
\hline & & Coef. & $95 \% \mathrm{CI}$ & $P$ & Adj. $r^{2}$ & & Coef. & $95 \% \mathrm{CI}$ & $P$ & $\overline{\text { Adj. } r^{2}}$ \\
\hline \multirow[t]{4}{*}{ Absolute } & $I$ & 450.3 & 373.6 & 0.0303 & 0.49 & $I$ & 745.0 & 534.2 & 0.0132 & 0.25 \\
\hline & $s_{1}$ & -86.49 & 410.9 & 0.6851 & & $S$ & -1743 & 1225 & 0.0117 & \\
\hline & $s_{2}$ & -1783 & 901.4 & 0.0012 & & & & & & \\
\hline & $T$ & 0.6608 & 0.0233 & $<0.0001$ & & & & & & \\
\hline \multirow[t]{4}{*}{ Relative } & $I$ & 19.88 & 26.74 & 0.1630 & 0.25 & $I$ & 36.02 & 34.31 & 0.0537 & 0.04 \\
\hline & $s_{1}$ & 26.82 & 29.83 & 0.0959 & & $S$ & -54.70 & 78.69 & 0.1890 & \\
\hline & $s_{2}$ & -58.96 & 51.57 & 0.0387 & & & & & & \\
\hline & $\bar{T}$ & 0.6103 & 0.0601 & $<0.0001$ & & & & & & \\
\hline
\end{tabular}

Notes: $I=$ intercept; $s_{1}=$ linear slope for segment $1(x<T) ; s_{2}=$ linear slope for segment $2(x>T) ; T=$ threshold or breakpoint; $S=$ slope of single-segment linear function; Coef. $=$ Coefficient $; \mathrm{CI}=$ confidence interval; Adj. $=$ Adjusted.

production. At low levels of disturbance, both the upper canopy and subcanopy sustained $\mathrm{ANPP}_{\mathrm{w}}$, with the relative contribution of the subcanopy increasing as disturbance severity increased. From low to high levels of disturbance, subcanopy production increased nearly 10 times following peak disturbance and contributed $40 \%$ to total $\mathrm{ANPP}_{\mathrm{w}}$ in highly disturbed plots (Fig. 4a); however, the response of subcanopy $\mathrm{ANPP}_{\mathrm{w}}$ was lower in plots exceeding the disturbance threshold (Fig. 4b).

As disturbance severity increased, production efficiency trended significantly upward (Fig. 5). Production

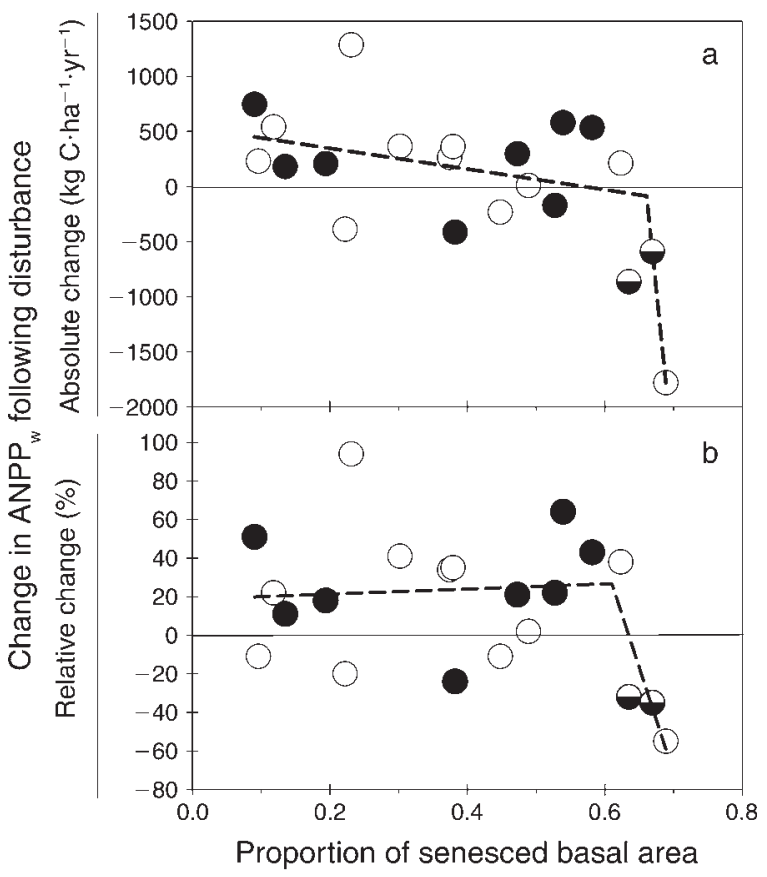

FIG. 2. (a) Absolute $\left(r^{2}=0.57\right.$ and $\left.P=0.0012\right)$ and (b) relative $\left(r^{2}=0.48, P=0.0014\right)$ changes in plot aboveground wood net primary production $\left(\mathrm{ANPP}_{\mathrm{w}}\right)$ before (2006-2010) and after (2010-2012) peak disturbance in relation to disturbance severity expressed as the fraction of senesced tree basal area. Solid and half-solid circles are the 10 intensive plots and open circles are the remaining 11 plots, with half-solid circles representing the two intensive plots past the threshold. Dashed lines are fitted piecewise regression segments.

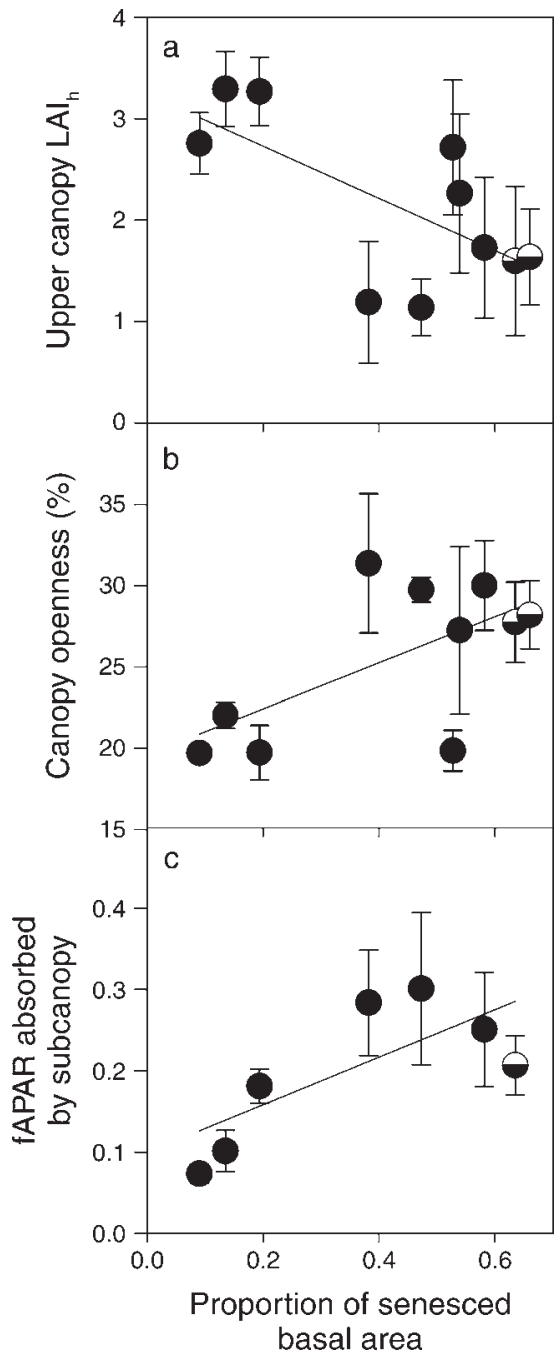

FIG. 3. Mean $( \pm \mathrm{SE})$ (a) plot upper canopy leaf area index $\left(\mathrm{LAI}_{\mathrm{h}}\right)\left(r^{2}=0.45, P=0.0348\right)$, (b) upper canopy openness $\left(r^{2}=\right.$ $0.40, P=0.0487)$, and (c) subcanopy fraction of absorbed photosynthetically active radiation (fAPAR) $\left(r^{2}=0.46, P=\right.$ 0.0645 ) in relation to disturbance severity, expressed as the fraction of senesced basal area. Data are for intensive plots, with half-solid circles representing plots past the disturbance threshold. 

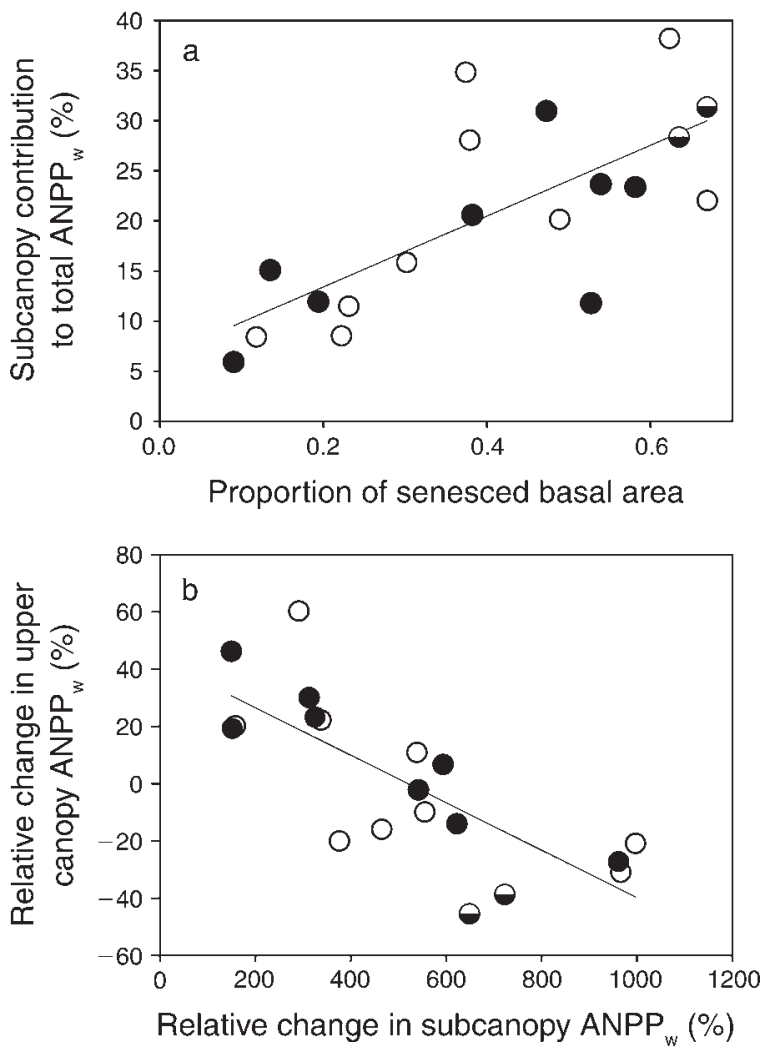

FIG. 4. (a) The relative contribution of plot-scale subcanopy aboveground wood net primary production $\left(\mathrm{ANPP}_{\mathrm{w}}\right)$ to total $\mathrm{ANNP}_{\mathrm{w}}$ in relation to disturbance severity expressed as the fraction of senesced basal area $\left(r^{2}=0.48\right.$ and $\left.P=0.0014\right)$, and (b) the relative change before and after peak disturbance in upper canopy and subcanopy $\mathrm{ANPP}_{\mathrm{w}}\left(r^{2}=0.58\right.$ and $\left.P=0.002\right)$. Solid and half-solid circles are the 10 intensive plots and open circles are the remaining 11 plots, with half-solid circles representing the two intensive plots past the disturbance threshold.

efficiency $\left(\mathrm{ANPP}_{\mathrm{w}} / \mathrm{LAI}_{\mathrm{h}}\right)$ nearly doubled across the gradient of disturbance severity, increasing because $\mathrm{ANPP}_{\mathrm{w}}$ remained stable in disturbance-resistant plots as $\mathrm{LAI}_{\mathrm{h}}$ declined. Plots that exceeded the disturbance threshold, however, had relatively low production efficiencies, falling below the $95 \%$ confidence interval for disturbance-resistant plots.

\section{Subcanopy leaf physiological, nitrogen, morphological responses to disturbance}

Disturbance-related increases in subcanopy growth and in production efficiency of the ecosystem coincided with leaf-level changes that are characteristic of sunadapted leaves. For example, we observed almost a twofold increase in red oak foliar $\mathrm{N}$ concentrations across a subplot gradient in upper-canopy openness (Fig. 6a). Red maple leaf percentage $\mathrm{N}$ responded similarly, with a significant $30 \%$ increase from low to high disturbance severity (Fig. 6b). American beech foliar $\mathrm{N}$ concentrations were not significantly correlated with canopy openness (Fig. 6c). Concomitant to the general trend of increasing foliar $\mathrm{N}$ in subcanopy vegetation was a significant increase in $A_{\max }$ with rising canopy openness for all three subcanopy species (Fig. 6d-f). In red oak and red maple there was a twofold increase in $A_{\max }$, with red oak showing the greatest absolute increase. Subcanopy leaves also responded morphologically to increasing light availability as canopy gaps formed from disturbance. Red maple doubled its LMA across the gradient of canopy openness (Fig. 6h), while red oak and American beech LMA did not change (Fig. 6g, i).

\section{DisCUSSION}

We have shown that forest production can exhibit high resistance to a range of disturbance levels, with the subcanopy playing a key role in compensating for the mortality of canopy trees. Our finding that production was sustained following the senescence of nearly twothirds of the upper canopy trees within a plot indicates a nonlinear response to rising disturbance severity in this forest ecosystem. We found that as disturbance severity increased, an incremental enhancement in subcanopy photosynthetic capacity, and consequently subcanopy $\mathrm{ANPP}_{\mathrm{w}}$, offset declines in the upper canopy until the disturbance threshold was exceeded. We attribute this increase in subcanopy production to higher light availability and physiological competency, which together likely drove increases in ecosystem-scale production efficiency. At the highest levels of disturbance severity, physiological and growth enhancements in the subcanopy did not sufficiently compensate for production losses from disturbance, though the reason for declining wood NPP beyond the threshold is not entirely

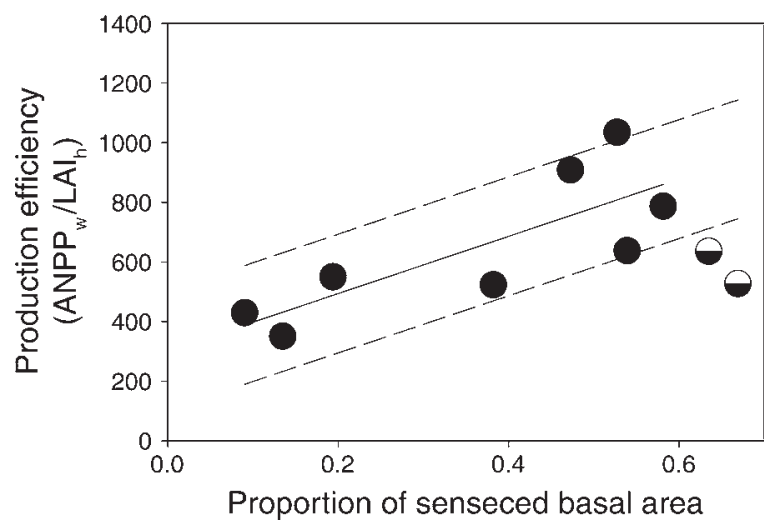

FIG. 5. Plot production efficiency following peak disturbance in relation to disturbance severity expressed as the fraction of senesced basal area. The (solid) regression line and (dashed) 95\% confidence interval lines are for intensive plots exhibiting resistance to disturbance (solid circles; $r^{2}=0.63$ and $P=0.0183$ ), with the two plots beyond the disturbance threshold (half-solid) significantly lower than the regression mean. Production efficiency is annual woody net primary production $\left(\mathrm{ANPP}_{\mathrm{w}}\right)$ divided by leaf area index $\left(\mathrm{LAI}_{\mathrm{h}}\right)$. 


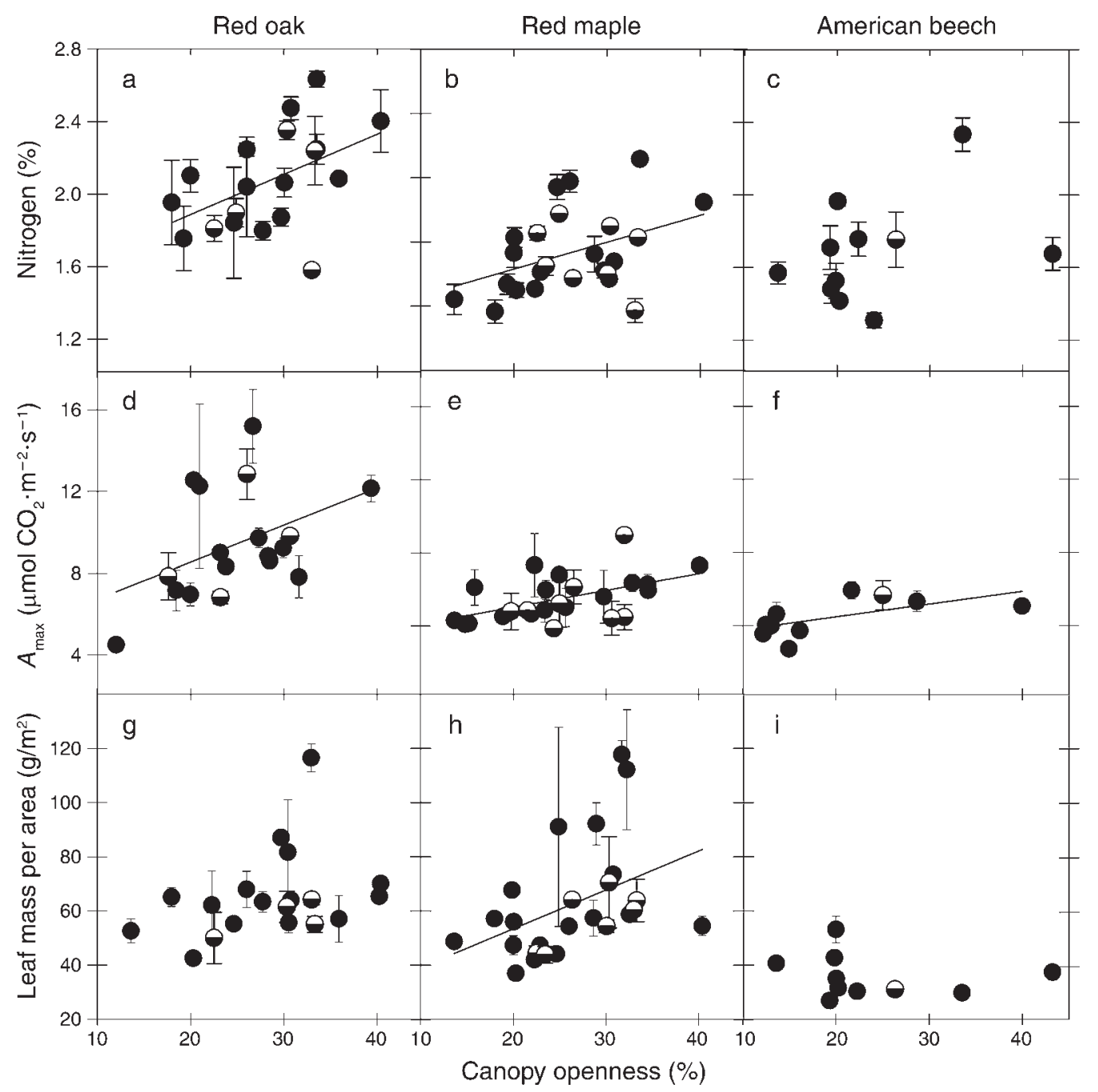

FIG. 6. (a-c) Leaf percentage nitrogen, (d-f) leaf maximum net $\mathrm{CO}_{2}$ assimilation $\left(A_{\max }\right)$, and (g-i) leaf mass per area ( \pm SE) of subcanopy species at $\sim 5 \mathrm{~m}$ height in relation to subplot canopy openness. Data are for subplots nested within intensive plots, with half-solid circles illustrating those beyond the disturbance threshold. Regressions lines are shown when $P \leq 0.1$.

clear. These results provide a mechanistic basis for functional resistance across a broad range of disturbance severities, showing that rates of compensatory growth were commensurate with disturbance severity until a threshold was reached.

A nonlinearly relationship between production and disturbance can be inferred from separate studies showing that forest growth changes very little or not at all following a single level of low-intensity disturbance (Granier et al. 2008, Amiro et al. 2010, Hicke et al. 2012, Gough et al. 2013) and, conversely, declines significantly at high disturbance severities (Campbell et al. 2004, Amiro et al. 2010). A high disturbance threshold, however, is not supported by terrestrial ecosystem models that simulate declines in production (BondLamberty et al. 2014), and aquatic studies showing high functional sensitivity to the loss of a subset of primary producers (Cardinale et al. 2011). A nonlinear response to increasing disturbance severity by some ecosystems has important implications, indicating that some ecosystems undergo substantial structural shifts without a corresponding functional change.

We found that sustained production in disturbanceresistant plots corresponded with canopy structural changes that improved production efficiency rather than with rapid leaf area replacement. Production efficiency $\left(\mathrm{ANPP}_{\mathrm{w}} / \mathrm{LAI}_{\mathrm{h}}\right)$ increased in disturbance-resistant plots because $\mathrm{ANPP}_{\mathrm{w}}$ was stable as upper canopy $\mathrm{LAI}_{\mathrm{h}}$ declined; contrastingly, production efficiency was significantly lower in plots beyond the disturbance threshold. Unlike severe stand-replacing disturbance, more moderate disturbances that kill only a subset of trees increase rather than decrease canopy complexity (Cole and Lorimer 2005), which may increase the efficient use of 
growth-limiting resources (Niinemets 2007, Campbell et al. 2009, Hardiman et al. 2011, 2013b). The heterogeneous distribution of tree mortality following the girdling treatment at our site has significantly increased canopy gaps and more evenly distributed foliage vertically throughout the canopy (Hardiman et al. 2013a), structural features that are linked to higher leaf photosynthesis as light becomes more evenly distributed and penetrates deeper into the canopy (Niinemets 2007). In addition, a disturbance-related shift toward a younger, mixed canopy age structure at our site may have improved mean plant resource acquisition, with younger trees in a tropical forest, for example, exhibiting higher water transport rates than larger, older trees (Landsberg and Waring 1997).

At our site, subcanopy leaf physiology, morphology, and $\mathrm{N}$ status responses were generally proportional to disturbance-related changes in canopy openness and light availability, even in the most highly disturbed plots. With an increase in canopy openness, subcanopy leaves became more light-acclimated, with foliar N concentrations similar to those of upper canopy leaves at our site (Nave et al. 2011). Additionally, subcanopy species displayed significant increases in maximum leaf net $\mathrm{CO}_{2}$ assimilation across the disturbance gradient. LMA showed similar trends, though a morphological change was only significant in red maple. Other studies report comparably rapid leaf-level acclimation of nutrient status, physiology, and morphology to improved light availability (Naidu and DeLucia 1997, Niinemets 2007).

Undisturbed vegetation growth responded rapidly to tree mortality, compensating for production losses from senescent trees except at the highest levels of disturbance. The relative contribution of upper canopy and subcanopy vegetation to production was dependent upon the severity of disturbance, with subcanopy trees contributing more to $\mathrm{ANPP}_{\mathrm{w}}$ as disturbance levels increased. A similar production trade-off between upper canopy and subcanopy vegetation was observed following thinning in coniferous forest ecosystems (Sabo et al. 2008, Campbell et al. 2009). The subcanopy contribution to total $\mathrm{ANPP}_{\mathrm{w}}$ of up to $40 \%$ that we observed following peak disturbance was comparable to the upper limits reported for other forests following moderate disturbance (Mission et al. 2007, Sabo et al. 2008). A rapid and relatively large subcanopy response to disturbance at our site was possible because an intact sapling layer existed prior to disturbance (Gough et al. 2010). Additionally, subcanopy fAPAR increased significantly following disturbance owing to relatively low upper-canopy $\mathrm{LAI}_{\mathrm{h}}$ values at our site of 1.1 to 3.2, with Beer's Law dictating a nonlinear increase in light transmission through the upper canopy as LAI declines (Binkley et al. 2013). Patchy tree mortality in forests with high upper canopy LAI values would not prompt the same increase in light transmission and therefore not be expected to stimulate a comparably high subcanopy growth response (O'Hara et al. 2007).
Large declines in $\mathrm{ANPP}_{\mathrm{w}}$ beyond the disturbance threshold were associated with significantly lower subcanopy $\mathrm{ANPP}_{\mathrm{w}}$ and production efficiencies, but not diminished leaf level nutrient status or physiological capacity. These results, though informed by a limited sample size, indicate that declining production at the highest levels of disturbance was caused by stunted subcanopy growth rather than by lower leaf photosynthesis at the time of measurements. The precise cause of diminished subcanopy growth in plots beyond the disturbance threshold is not known, but could be the result of initial temporary photoinhibition as light availability increased (Mulkey and Pearcy 1992, Naidu and DeLucia 1997), water limitation as forest floor radiation increased evaporation (Gray et al. 2002, Matheny et al. 2014), or poor subcanopy establishment prior to disturbance (Campbell et al. 2009). Though NPP at our site is nitrogen (N) limited (Nave et al. 2009), leaching following disturbance was minimal (Nave et al. 2011, 2014), consistent with our observation that foliar nitrogen concentrations were comparable in plots before and after the disturbance severity threshold. Nevertheless, an unexpectedly small sample size beyond the disturbance threshold precludes a more definitive interpretation of what caused an abrupt loss of functional resistance.

Our findings have implications for forest $\mathrm{C}$ management as moderate disturbances broadly increase in frequency and extent (Amiro et al. 2010, Hicke et al. 2012). Our results suggest that management strategies aimed at preventing low-intensity disturbances from pathogens and insects, for example, may not be required to maintain $\mathrm{C}$ storage in biomass. Additionally, moderate disturbances may minimally alter forest $\mathrm{C}$ storage while increasing ecologically desirable physical complexity, an outcome that is in stark contrast to severe stand-replacing disturbances that greatly reduce ecosystem complexity (Seymour et al. 2002, Hardiman et al. 2013a). Physical complexity introduced through moderate disturbance may instead sustain or enhance ecosystem services, including animal biodiversity and nutrient retention (Thompson et al. 2011), a notion that forms the basis for emergent sustainable forest management approaches that balance partial timber harvests and ecological objectives (Franklin et al. 2002).

We caution that sustained production following moderate disturbance is not universal, with sensitivity to disturbance varying among ecosystems (Amiro et al. 2010, Cardinale et al. 2011). Forest ecosystems that are severely resource limited prior to disturbance may be more vulnerable to disturbances that further reduce the availability of growth-limiting resources (Waring et al. 1981, McMurtrie et al. 1994). For example, small disturbance-related changes in water availability produced comparably large changes in ecosystem functioning in already severely water-limited ecosystems (Breshears et al. 2009, Carnicer et al. 2011). Further uncertainty remains in understanding how the timing, 
distribution, and cause of tree mortality affects production resilience (Gough et al. 2013). Finally, we note that wood NPP resilience may not track other C fluxes following disturbance, since detritus and biomass pools respond differently in space and time to perturbation (Harmon et al. 2011, Anderson-Teixeira et al. 2013); thus, the implications of disturbance severity gradients for the total $\mathrm{C}$ balance (i.e., NEP) remain uncertain. Elucidating the underlying mechanisms that support functional resilience or, at high disturbance severities, functional decline is critical to improving forecasts of $\mathrm{C}$ storage as disturbances increase globally (Williams et al. 2012).

\section{ACKNOWLEDGMENTS}

We are grateful for reviews provided by Dr. Richard Waring and an anonymous reviewer, and for feedback from Derek Johnson, Paul Bukaveckas, and Suzanne Robertson. We thank Brady Hardiman for help with fAPAR calculations. We acknowledge the University of Michigan Biological Station for the use of their facilities. This research was supported by the Climate and Environmental Sciences Division, Office of Science, U.S. Department of Energy (DOE) [Award No. DESC0006708].

\section{Literature Cited}

Amiro, B. D., et al. 2010. Ecosystem carbon dioxide fluxes after disturbance in forests of North America. Journal of Geophysical Research: Biogeosciences 115. http://dx.doi. org/10.1029/2010JG001390

Anderson-Teixeira, K. J., A. D. Miller, J. E. Mohan, T. W. Hudiburg, B. D. Duval, and E. H. Delucia. 2013. Altered dynamics of forest recovery under a changing climate. Global Change Biology 19:2001-2021.

Binkley, D., O. C. Campoe, M. Gspaltl, and D. I. Forrester. 2013. Light absorption and use efficiency in forests: Why patterns differ for trees and stands. Forest Ecology and Management 288:5-13.

Bond-Lamberty, B., J. Fisk, J. A. Holm, V. Bailey, and C. M. Gough. 2014. Moderate forest disturbance as a stringent test for gap and big-leaf models. Biogeosciences Discussion 11: 11217-11248.

Breshears, D. D., O. B. Myers, C. W. Meyer, F. J. Barnes, C. B. Zou, C. D. Allen, and W. T. Pockman. 2009. Tree die-off in response to global change-type drought: mortality insights from a decade of plant water potential measurements. Frontiers in Ecology and the Environment 7:185-189.

Campbell, J. L., G. Alberti, J. Martin, and B. E. Law. 2009. Carbon dynamics of a ponderosa pine plantation following a thinning treatment in the northern Sierra Nevada. Forest Ecology and Management 257:453-463.

Campbell, J. L., O. J. Sun, and B. E. Law. 2004. Disturbance and net ecosystem production across three climatically distinct forest landscapes. Global Biogeochemical Cycles 18:GB4017, http://dx.doi.org/10.1029/2004GB002236

Cardinale, B. J., K. L. Matulich, D. U. Hooper, J. E. Bryes, E. Duffy, L. Gamfeldt, P. Balvanera, M. I. O'Connor, and A. Gonzalez. 2011. The functional role of producer diversity in ecosystems. American Journal of Botany 98:572-592.

Carnicer, J., M. Coll, M. Ninyerola, X. Pons, G. Sanchez, and J. Penuelas. 2011. Widespread crown condition decline, food web disruption, and amplified tree mortality with increased climate change-type drought. Proceedings of the National Academy of Sciences USA 108:1474-1478.

Cole, W. G., and C. G. Lorimer. 2005. Probabilities of smallgap capture by sugar maple saplings based on height and crown growth data from felled trees. Canadian Journal of Forest Research 35:643-655.
Edburg, S. L., J. A. Hicke, D. M. Lawrence, and P. E. Thornton. 2011. Simulating coupled carbon and nitrogen dynamics following mountain pine beetle outbreaks in the western United States. Journal of Geophysical Research: Biogeosciences 116.

Franklin, J. F., T. A. Spies, R. Van Pelt, A. B. Carey, D. A. Thornburgh, D. R. Berg, D. B. Lindenmayer, M. E. Harmon, W. S. Keeton, D. C. Shaw, K. Bible, and J. Chen. 2002. Disturbance and structural development of natural forest ecosystems with silvicultural implications, using Douglas-fir forests as an example. Forest Ecology and Management 155:399-423.

Goetz, S. J., B. Bond-Lamberty, B. E. Law, J. A. Hicke, C. Huang, R. A. Houghton, S. McNulty, T. O'Halloran, M. Harmon, J. H. Meddens, E. M. Pfeifer, D. Mildrexler, and E. S. Kasishke. 2012. Observations and assessments of forest carbon dynamics following disturbance in North America. Journal of Geophysical Research 117:1-17.

Gough, C. M., B. S. Hardiman, L. E. Nave, G. Bohrer, K. D. Maurer, C. S. Vogel, K. J. Nadelhoffer, and P. S. Curtis. 2013. Sustained carbon uptake and storage following moderate disturbance in a Great Lakes forest. Ecological Applications 23:12012-1215.

Gough, C. M., C. S. Vogel, B. Hardiman, and P. S. Curtis. 2010. Wood net primary production resilience in an unmanaged forest transitioning from early to middle succession. Forest Ecology and Management 260:36-41.

Gough, C. M., C. S. Vogel, H. P. Schmid, H. B. Su, and P. S. Curtis. 2008. Multi-year convergence of biometric and meteorological estimates of forest carbon storage. Agricultural and Forest Meteorology 148:158-170.

Granier, A., N. Breda, B. Longdoz, P. Gross, and J. Ngao. 2008. Ten years of fluxes and stand growth in a young beech forest at Hesse, north-eastern France. Annals of Forest Science 65:13.

Gray, A. N., T. A. Spies, and M. J. Easter. 2002. Microclimatic and soil moisture responses to gap formation in coastal Douglas-fir forests. Canadian Journal of Forest Research 32: 332-343.

Gunderson, L. H. 2000. Ecological resilience in theory and application. Annual Review of Ecology and Systematics 31: 425-439.

Hancock, J. E., M. A. Arthur, K. C. Weathers, and G. M. Lovett. 2008. Carbon cycling along a gradient of beech bark disease impact in the Catskill Mountains, New York. Canadian Journal of Forest Research 38:1267-1274.

Hardiman, B. S., G. Bohrer, C. M. Gough, and P. S. Curtis. 2013a. Canopy structural changes following widespread mortality of canopy dominant trees. Forests 4:537-552.

Hardiman, B. S., G. Bohrer, C. M. Gough, C. S. Vogel, and P. S. Curtis. 2011. The role of canopy structural complexity in wood net primary production of a maturing northern deciduous forest. Ecology 92:1818-1827.

Hardiman, B. S., C. M. Gough, and B. Halperin. $2013 b$. Maintaining high rates of carbon storage in old forests: a mechanism linking canopy structure to forest function. Forest Ecology and Management 298:111-119.

Harmon, M. E., B. Bond-Lamperty, J. Tang, and R. Vargas. 2011. Heterotrophic respiration in disturbed forests: a review with examples from North America. Journal of Geophysical Research: Biogeosciences 116:2005-2012.

He, L., V. Y. Ivanov, G. Bohrer, K. D. Maurer, C. S. Vogel, and M. Moghaddam. 2014. Effects of fine-scale soil moisture and canopy heterogeneity on energy and water fluxes in a northern temperate mixed forest. Agricultural and Forest Meteorology 184:243-256.

Hicke, J. A., et al. 2012. Effects of biotic disturbances on forest carbon cycling in the United States and Canada. Global Change Biology 18:7-34.

Landsberg, J. J., and R. H. Waring. 1997. A generalized model of forest productivity using simplified concepts of radiation- 
use efficiency, carbon balance and partitioning. Forest Ecology and Management 95:209-228.

Matheny, A. M., et al. 2014a. Characterizing the diurnal patterns of errors in the prediction of evapotranspiration by several land-surface models: an NACP analysis. Journal of Geophysical Research: Biogeosciences 119:1458-1473.

Matheny, A. M., et al. 2014b. Species-specific transpiration responses to intermediate disturbance in a northern hardwood forest. Journal of Geophysical Research: Biogeosciences 119:2292-2311.

Matteo, D., G. Bohrer, J. Nietz, K. Maurer, C. M. Gough, and P. S. Curtis. 2013. Multi-variate conditional granger causality analysis for lagged response of soil respiration in a temperate forest. Entropy 15:4266-4284.

McCrady, R. L., and E. J. Jokela. 1998. Canopy dynamics, light interception, and radiation use efficiency of selected loblolly pine families. Forest Science 44:64-72.

McKinley, D. C., et al. 2011. A synthesis of current knowledge on forests and carbon storage in the United States. Ecological Applications 21:1902-1924.

McMurtrie, R. E., H. L. Gholz, S. Linder, and S. T. Gower. 1994. Climatic factors controlling the productivity of pine stands: a model-based analysis. Ecological Bulletins 43:173188.

Mission, L., et al. 2007. Partitioning forest fluxes with overstory and understory eddy-covariance measurements: a synthesis based on FLUXNET data. Agricultural and Forest Meteorology 144:14-32.

Mulkey, S. S., and R. W. Pearcy. 1992. Interactions between acclimation and photoinhibition of photosynthesis of a tropical forest understorey herb, Alocasia macrorrhiza, during simulated canopy gap formation. Functional Ecology 6:719-729.

Naidu, S. L., and E. H. DeLucia. 1997. Acclimation of shadedeveloped leaves on saplings exposed to late-season canopy gaps. Tree Physiology 17:367-376.

Nave, L., E. D. Vance, C. W. Swanston, and P. S. Curtis. 2009. Harvest impacts on soil carbon storage in temperate forests. Forest Ecology and Management 259:857-866.

Nave, L. E., et al. 2011. Disturbance and the resilience of coupled carbon and nitrogen cycling in a north temperate forest. Journal of Geophysical Research: Biogeosciences 116: G04016.

Nave, L. E., J. P. Sparks, J. Le Moine, B. S. Hardiman, K. J. Nadelhoffer, J. M. Tallant, C. S. Vogel, B. D. Strahm, and P. S. Curtis. 2014. Changes in soil nitrogen cycling in a northern temperate forest ecosystem during succession. Biogeochemistry 121:471-488.

Niinemets, U. 2007. Photosynthesis and resource distribution through plant canopies. Plant, Cell and Environment 30: 1052-1071.
Nobis, M., and U. Hunziker. 2005. Automatic thresholding for hemispherical canopy photographs based on edge detection. Agricultural and Forest Meterology 128:243-250.

O'Hara, K. L., P. T. Stancioiu, and M. A. Spencer. 2007. Understory stump sprout development under variable canopy density and leaf area in coast redwood. Forest Ecology and Management 244:76-85.

Pan, Y., et al. 2011. A large and persistent carbon sink in the world's forest. Science 333:988-993.

Peckham, S. D., S. T. Gower, C. H. Perry, B. T. Wilson, and K. M. Stueve. 2013. Modeling harvest and biomass removal effects on the forest carbon balance of the Midwest, USA. Environmental Science \& Policy 25:22-35.

R Development Core Team. 2014. R: a language and environment for statistical computing (version R 3.1.0). R Foundation for Statistical Computing, Vienna, Austria.

Sabo, K. E., S. C. Hart, C. H. Sieg, and J. D. Bailey. 2008. Tradeoffs in overstory and understory aboveground net primary productivity in Southwestern ponderosa pine stands. Forest Science 54:408-416.

Seymour, R. S., A. S. White, and P. G. deMaynadier. 2002. Natural disturbance regimes in northeastern North Americaevaluating silvicultural systems using natural scales and frequencies. Forest Ecology and Management 155:357-367.

SPSS. 2005. SPSS 12.5 for Windows. SPSS, Chicago, Illinois, USA.

Thompson, I. D., K. Okabe, J. M. Tylianakis, P. Kumar, E. G. Brockerhoff, N. A. Schellhorn, J. A. Parrotta, and R. Nasi. 2011. Forest biodiversity and the delivery of ecosystem goods and services: translating science into policy. BioScience 61: 972-981.

Tilman, D., P. B. Reich, J. Knops, D. A. Wedin, T. Mielke, and C. Lehman. 2001. Diversity and productivity in a long-term grassland experiment. Faculty Publications in the Biological Sciences. Paper 151.

Tobin, M. F., and P. B. Reich. 2009. Comparing indices of understory light availability between hemlock and hardwood forest patches. Canadian Journal of Forest Research 39: 1949-1957.

Toms, J. D., and M. L. Lesperance. 2003. Piecewise regression: a tool for identifying ecological thresholds. Ecology 84:20342041.

Waring, R. H., K. Newman, and J. Bell. 1981. Efficiency of tree crowns and stemwood production at different canopy leaf densities. Forestry 54:129-137.

Williams, C. A., G. J. Collatz, J. Masek, and S. N. Goward. 2012. Carbon consequences of forest disturbance and recovery across the conterminous United States. Global Biogeochemical Cycles 26.

Yang, Y. H., Y. Q. Luo, and A. C. Finzi. 2011. Carbon and nitrogen dynamics during forest stand development: a global synthesis. New Phytologist 190:977-989.

\section{Supplemental Material}

\section{Ecological Archives}

The Appendix is available online: http://dx.doi.org/10.1890/14-1810.1.sm 